\title{
John Cottingham, Cartesian Reflections. Essays on Descartes's Philosophy
}

\section{Laura Rescia}

\section{(2) OpenEdition}

1 Journals

\section{Edizione digitale}

URL: https://journals.openedition.org/studifrancesi/6610

DOI: 10.4000/studifrancesi.6610

ISSN: 2421-5856

\section{Editore}

Rosenberg \& Sellier

\section{Edizione cartacea}

Data di pubblicazione: 1 septembre 2010

Paginazione: 358

ISSN: 0039-2944

\section{Notizia bibliografica digitale}

Laura Rescia, «John Cottingham, Cartesian Reflections. Essays on Descartes's Philosophy», Studi

Francesi [Online], 161 (LIV | II) | 2010, online dal 30 novembre 2015, consultato il 20 novembre 2021. URL: http://journals.openedition.org/studifrancesi/6610 ; DOI: https://doi.org/10.4000/studifrancesi. 6610

Questo documento è stato generato automaticamente il 20 novembre 2021.

\section{(c) $(1) \ominus$}

Studi Francesi è distribuita con Licenza Creative Commons Attribuzione - Non commerciale - Non opere derivate 4.0 Internazionale. 


\title{
John Cottingham, Cartesian Reflections. Essays on Descartes's Philosophy
}

\author{
Laura Rescia
}

\section{NOTIZIA}

JOHN соттingham, Cartesian Reflections. Essays on Descartes's Philosophy, Oxford, Oxford University Press, 2008, pp. 332.

1 Opera di un eminente filosofo, questo libro associa la grande precisione e profondità derivante dalla ricerca accademica ad una straordinaria semplicità di esposizione, favorita da una scrittura particolarmente limpida. Si tratta di una raccolta di articoli precedentemente pubblicati, qui in parte rielaborati e introdotti da un nuovo capitolo che ne illustra e precisa la direzione di ricerca.

2 L'A. dichiara nella sua introduzione di voler offrire una lettura di Descartes che si allontani dalla vulgata del filosofo del dualismo corpo-mente, per restituire la ricchezza di tutti gli aspetti fondamentali del suo pensiero, con un'attenzione particolare e inconsueta nella tradizione degli studi cartesiani al debito nei confronti dei predecessori e alla presenza del divino nel suo pensiero. I quattordici capitoli sono raggruppati in tre sezioni: «Descartes nella storia della filosofia»; «Mente e Mondo»; «Etica e Religione».

Atteggiamento ormai raro nei paesi anglosassoni, e tanto più apprezzabile, le citazioni vengono fornite in lingua originale, e i rinvii bibliografici in nota adottano il sistema estensivo in luogo del più sintetico rinvio all'anno di pubblicazione; la bibliografia è altamente selettiva. 